\title{
INVESTIGATION OF METHODS, MODELS AND INFORMATION TECHNOLOGIES OF EXPERT ESTIMATION OF RESULTS OF TECHNOLOGICAL PROCESS
}

\section{ДОСЛІДЖЕННЯ МЕТОДІВ, МОДЕЛЕЙ \\ ТА ІНФОРМАЦІЙНИХ ТЕХНОЛОГІЙ ЕКСПЕРТНОГО ОЦІНЮВАННЯ РЕЗУЛЬТАТІВ ТЕХНОЛОГІЧНОГО ПРОЦЕСУ}

\author{
Tamara V. Kukhtyk \\ ditmtvk@icloud.com \\ ORCID: 0000-0002-2000-3669 \\ Iryna A. Getman \\ getman_irina@ukr.net \\ ORCID: 0000-0003-1835-4256
}

Maryna A. Derzhevetska

marina_d.a@ukr.net

ORCID: 0000-0002-9952-4992
Т. В. Кухтик ${ }^{1}$, докт. техн. наук, професор

I. А. Гетьман ${ }^{2}$, канд. техн. наук, доцент

М. А. Держевецька ${ }^{3}$, канд. екон. наук

\section{${ }^{1}$ Donbass Institute of Technology and Management of Academician Yuriy Bugay International Scientific and Technical University, Kramatorsk \\ ${ }^{1}$ Донбаський інститут техніки та менеджменту Міжнародного науково-технічного університету імені академіка Юрія Бугая, м. Краматорськ \\ ${ }^{2}$ Donbas State Engineering Academy, Kramatorsk \\ ${ }^{2}$ Донбаська державна машинобудівна академія, м. Краматорськ \\ ${ }^{3}$ Donetsk National Medical University, Kramatorsk \\ ${ }^{2}$ Донеиький національний медичний університет, м. Краматорськ}

\begin{abstract}
The question of development of the software complex for expert estimation of the results of the technological process has been considered. The analysis of types of technological processes has been carried out. It has been proved that for any process it is necessary to conduct its expert evaluation. The existing methods of expert evaluation have been analyzed. The methods that are most suitable for evaluating the technological processes have been chosen. It has been proved that for the correct expert assessment of various technological processes it is necessary to determine the ultimate goal of such an assessment. A clear wording of the questions on the basis of which the questionnaires are made, and which later will be filled with experts, has been necessary. The main criteria for evaluating the results of the technological process have been highlighted. For each criterion, an appropriate set of factors has been established. The main problem of selection of experts has been selected and formed. It has been established that when selecting experts, it is necessary to take into account the moment of personal interest, which entails receiving a biased assessment. The mathematical model has been developed, which requires an expert assessment of the competence of the expert for further inclusion in the expert group. It has been determined by what parameters it is necessary to assess the consistency and competence of experts. It has been proved that after the examination it is necessary to conduct a statistical analysis of the results and, if necessary, take measures to reduce the errors made during the examination. The main business processes of the subject area on the basis of SADT-diagrams have been considered. The main entities have been highlighted when creating use case diagrams. The class diagram has been developed. When developing a software product, an approach has been based on object-oriented design using the $\mathrm{C} \#$ programming language was used. The choice of the appropriate language has been justified in the article. As a result of the work performed two methods of expert assessments have been used to evaluate the results of the technological process. The analysis of the correctness of the calculations has been provided for comparison of statistical data obtained at the stage of expert evaluation.
\end{abstract}

Key words: technological process; methods of expert estimation; expert; indicators; results; evaluation; program-methodical complex. 
Анотація. Розглянуто питання розробки програмного комплексу для експертної оцінки результатів технологічного процесу. Проведено аналіз типів технологічних процесів. Доведено, що для будь-якого процесу необхідно проводити його експертну оцінку. Проаналізовано наявні методи експертної оцінки. Вибрано методи, найбільш підходящі для оцінки технологічних процесів. Доведено, що для правильної експертної оцінки різних технологічних процесів необхідно визначити кінцеву мету такої оцінки. Необхідно чітке формулювання питань, на основі яких складаються анкети, що згодом будуть заповнені експертами. Висвітлено основні критерії оцінки результатів технологічного процесу. Для кожного критерію встановлено відповідний набір факторів. Вибрано та сформовано основну проблему відбору експертів. Встановлено, що у разі підбору експертів необхідно враховувати момент особистої зацікавленості, що тягне за собою отримання упередженої оцінки. Розроблена математична модель, яка вимагає експертної оцінки компетентності експерта для подальшого включення до групи експертів. Визначено, за якими параметрами необхідно оцінювати послідовність та компетентність експертів. Доведено, що після проведення експертизи необхідно провести статистичний аналіз результатів і у разі необхідності вжити заходів для зменшення помилок, допущених під час експертизи. Розглянуто основні бізнес-процеси предметної галузі на основі SADT-діаграм. Основні сутності були виділені під час створення діаграм випадків використання. Розроблено схему класів. Під час розробки програмного продукту підхід базувався на об'єктно-орієнтованому дизайні з використанням мови програмування С\#. Вибір відповідної мови обгрунтовано у статті. У результаті проведеної роботи для оцінки результатів технологічного процесу були використані два методи експертних оцінок. Проведено аналіз правильності розрахунків для порівняння статистичних даних, отриманих на етапі експертної оцінки.

Ключові слова: технологічний процес; методи експертної оцінки; експерт; показники; результати; оцінювання; програмно-методичний комплекс.

\section{ПОСТАНОВКА ЗАДАЧІ}

Нині методи експертного оцінювання широко застосовуються для розв'язання проблем різного характеру. У різних галузях, об'єднаннях і на підприємствах діють постійні або тимчасові експертні комісії, що формують рішення 3 різних складних питань. Експертні методи застосовують зараз у ситуаціях, коли вибір, обгрунтування і оцінка наслідків рішень не можуть бути виконані на основі точних розрахунків. Такі ситуації нерідко виникають під час розробки сучасних проблем технологічного процесу і особливо під час прогнозування та довгострокового планування. Останніми роками експертні оцінки знаходять широке застосування у соціальнополітичному i науково-технічному прогнозуванні, в плануванні народного господарства, галузей, об'єднань, у розробці великих науково-технічних, економічних і соціальних програм, у розв'язанні окремих проблем управління. У ході розвитку суспільного виробництва зростають не тільки складність управління, а й вимоги до якості прийняття рішень. Для того щоб підвищувати обгрунтованість рішень і враховувати велику кількість факторів, що впливають на їх результати, необхідний різнобічний аналіз, заснований як на розрахунках, так і на аргументованих судженнях керівників і фахівців, знайомих зі станом справ і перспективами розвитку в різних сферах практичної діяльності. Застосування експертних методів забезпечує активну і цілеспрямовану участь фахівців на всіх етапах прийняття рішень, що дозволяє істотно підвищити їх якість і ефективність. $Є$ велика кількість методів експертного оцінювання, але кожний з них має різні властивості та характеристики оцінювання.

\section{АНАЛІЗ ОСТАННІХ ДОСЛІДЖЕНЬ І ПУБЛІКАЦІЙ}

Аналіз наявних експертних методів для автоматизації експертного оцінювання результатів технологічного процесу є предметом інтенсивних наукових досліджень [1].

На базі оцінок експертів буде отримана загальна інформація про досліджуваний процес та формується рішення, що задається метою експертизи. Вибір того чи іншого методу залежить від складності розв'язуваної проблеми, форми, в якій надані думки експертів, мети експертизи [2].

Для обробки результатів опитування використовуються методи математичної статистики. Залежно від мети експертизи під час обробки оцінок можуть вирішуватися такі проблеми: формування узагальненої оцінки; визначення відносних ваг об'єктів; встановлення ступеня узгодженості експертів та ін. [3].

Дослідженням наявних методів експертного оцінювання займались: Д. Гордон, О. Хелмер, В. Глушков, Ю. Сршов. Л. Смірнов та ін. Також велику кількість інформації про методи експертного оцінювання подає у своїх книжках О. Орлов.

\section{ВІДОКРЕМЛЕННЯ НЕ ВИРІШЕНИХ РАНІШЕ ЧАСТИН ЗАГАЛЬНОӦ ПРОБЛЕМИ}

Внаслідок того, що кількість традиційних методів експертного оцінювання досить велика і суттєво велика кількість методів і алгоритмів їх здійснення, для того щоб оцінити вклад того чи іншого методу в загальну оцінку результатів технологічного процесу, необхідно провести аналіз наявних методів експертного оцінювання.

Перед початком експертного дослідження необхідно чітко визначити його мету та сформувати від- 


\section{КОМП'ЮТЕРНІ НАУКИ ТА ІНФОРМАЦІЙНІ ТЕХНОЛОГІЇ №3-2020}

повідні запитання до експертів. Далі необхідно визначитись із методом експертного оцінювання [4]. Найбільш відомими методами експертного оцінювання є: метод «Дельфі» [5]; метод ранжування [6]; метод аналізу ієрархій [7]; бальний метод [8].

Усі перераховані методи мають свій алгоритм та свої строки проведення та потреби в кількості експертів.

Експерти перед винесенням судження повинні розгорнуто розглянути відомості про технологічний процес. Для проведення цієї процедури необхідно підготувати матеріали про технологічний процес, довідкові матеріали, анкети та статистичні дані. Потрібно уникати таких помилок: згадувати розробників матеріалу, виділяти той чи інший технологічний процес [9].

Проблема підбору експертів є найбільш складною. Експерти повинні мати досвід у сферах, що відповідають поставленому завданню. Під час підбору експертів необхідно враховувати момент особистої зацікавленості, який може стати значною перепоною для отримання об'єктивної думки. Після експертизи необхідно провести статистичний аналіз результатів, тобто:

1) оцінити узгодженість експертів. За відсутності значної узгодженості експертів необхідно виявити причини неузгодженості та визначити причини відсутності узгодженості експертів;

2) оцінити похибку дослідження.

На базі оцінок експертів отримано узагальнену інформацію про технологічний процес та сформовано рішення. Залежно від цілей дослідження можуть вирішуватись такі проблеми:

1) формування узагальненої оцінки;

2) визначення відносних ваг об'єктів;

3) встановлення узгодженості думок експертів [10].

\section{МЕТА ДОСЛІДЖЕННЯ}

Метою роботи є створення програмного комплексу для проведення експертного оцінювання результатів технологічного процесу. Оцінювання буде проводитись двома методами: методом ранжування та бальним методом.

\section{ОСНОВНИЙ МАТЕРІАЛ}

Експерти мають оцінити технологічний процес за 10-бальною шкалою, а критеріями оцінки виступають такі фактори: $X_{1}$ - надійність; $X_{2}$ - продуктивність; $X_{3}$ - собівартість; $X_{4}$ - внутрішньошарова похибка; $X_{5}$ - набута похибка; $X_{6}$ - безпечність; $X_{7}$ - норма часу; $X_{8}$ - трудомісткість та інше.

Після отримання відповідей експертів необхідно провести їх оцінку. Це дозволяє: оцінити узгодженість думок експертів; оцінити похибку дослідження; побудувати модель властивостей об'єкта на основі відповідей експертів. Результати експертного оцінювання оформляються у вигляді звіту. У звіті вказується мета дослідження, склад експертів, отримана оцінка та статистичний аналіз результатів.
На базі оцінок експертів виходить інформація про досліджувані технологічні процеси за певним пріоритетом. Перед самим дослідженням необхідно вказати експерту, за яким пріоритетом (наприклад, собівартість) буде проходити анкетування.

Для того щоб визначити узгодженість експертів, необхідно провести розрахунок коефіцієнта конкордації. Коефіцієнт конкордації Кендала, або по-іншому Коефіцієнт множинної рангової кореляції, потрібен для того, щоб виявити узгодженість думок експертів по декількох факторах [11].

Значення коефіцієнта конкордації Кендала розраховується за формулою:

$$
W=\frac{12 \cdot S}{m^{2} \cdot\left(n^{2}-n\right)}
$$

де $m$ - кількість експертів; $n$ - кількість факторів; $S$ - сума квадратів різниць рангів (відхилень від середнього).

Сума квадратів різниць рангів розраховується за формулою:

$$
S=\sum_{j=1}^{n}\left(\sum_{i=1}^{n} X_{i}-\frac{1}{2} m(n+1)\right)^{2}
$$

Коефіцієнт $W$ змінюється в діапазоні від 0 до 1 . Якщо він дорівнює одиниці, то це означає, що всі експерти присвоїли об'єктам однакові ранги. Чим ближче значення до нуля, тим менш узгодженими є оцінки експертів.

Необхідно розрахувати коефіцієнти компетентності кожного $з$ експертів. Суть цього обчислення полягає в припущенні про те, що компетентність експертів слід оцінювати за рівнем узгодженості їх оцінок з груповою оцінкою об'єктів.

Компетентність експерта розраховується за формулою:

$$
K_{j}=\frac{\sum_{j}\left(X_{i j} \cdot M_{i}\right)}{\sum_{i}\left(M_{i} \cdot S_{i}\right)}
$$

де $K_{j}$ - коефіцієнт компетентності $j$-го експерту; $X_{i j}$ - оцінка $i$-го об'єкта, поставлена $j$-им експертом; $M_{i}-$ середня оцінка $i$-го об'єкта; $S_{i}$ - сума оцінок $i$-го об'єкта.

Для визначення довірчого інтервалу $I_{x i}=\left(x_{i}-\varepsilon_{p i}, x_{i}+\varepsilon_{p i}\right)$, із заданою довірчою ймовірністю Р, можна використовувати точний і наближений методи. Найбільш практичний наближений метод, який за великого числа експертів $(m \geq 10)$ дає інтервальну оцінку, близьку до оцінки за допомогою точного методу. У разі використання такого методу величина $\varepsilon_{p i}$, що визначає межі довірчого інтервалу, розраховується за формулою 4:

$$
\varepsilon_{p i}=t_{p} \cdot \frac{\sigma_{i}}{\sqrt{m}}
$$

де $t_{p}$ - коефіцієнт, що залежить від заданої довірчої вірогідності.

Довірчий інтервал-термін, який використовується в математичній статистиці під час інтервальної оцін- 
ки статистичних параметрів, кращий у разі невеликого обсягу вибірки, ніж точковий. Довірчим називають інтервал, який покриває невідомий параметр із заданою надійністю. Розраховується за формулою [10]:

$$
I_{\bar{X}}=\left(\bar{X}-\varepsilon_{p i}, \bar{X}+\varepsilon_{p i}\right),
$$

де $\bar{X}$ - середня оцінка кожного об'єкта; $\varepsilon_{p i}-$ межа довірчого інтервалу.

Для початку проведення процесу експертного оцінювання результатів технологічного процесу необхідно вибрати необхідну кількість експертів. Далі необхідно вказати експерту, за яким методом буде проводитись оцінювання. Далі формується анкета, в яку експерт виставляє оцінки за кожний параметр. Відтак формується завдання для розрахунку. Наприкінці проводиться розрахунок якості ТП. Потім виводиться на екран результат оцінювання та статистична інформація (наприклад, коефіцієнт варіації, коефіцієнт конкордації та ін.).

На вхід подаються «Критерії оцінки ТП» та «Статистична оцінка точності», «Критерії якості ТП», «Дані експертів», «Алгоритм методу», на виході отримують «Результат оцінювання ТП» та «Статистична інформація». Реалізація активностей здійснюється «виконавцями» - експертом та ПП. Управління здійснюється алгоритмом та документацією.

На рисунку 1 представлена SADT-діаграма 0-го рівня для бізнес-процесу «Експертне оцінювання результатів технологічного процесу»

Можна виокремити одну роль - експерта. Роль експерта полягає в оцінці якості технологічного процесу та отриманні узагальненої оцінки якості ТП. Експерт має можливість працювати 3 даними експерта (додати, вибрати, видалити). Експерт має можливість працювати з оцінками експертів: додати або видали їх із програми. Також він повинен працювати 3 критеріями ТП: додати критерії та застосовувати вагові коефіцієнти. Також експерт повинен виставити оцінки до спеціальної анкети. Насамкінець експерту необхідно вибрати метод оцінювання та виконати розрахунок якості ТП.

На рисунку 2 представлена діаграма прецедентів «Автоматизація експертного оцінювання результатів технологічного процесу».

Система зберігає дані про експерта. До анкети включаються дані експерта. До анкети також входять параметри технологічного процесу. Також оцінки заносяться до анкети. Сама анкета створює завдання, яке виконує метод. Методи, які зберігає система, називаються «Метод 1» та «Метод 2»

Діаграма класів для автоматизації експертного оцінювання результатів технологічного процесу показана на рисунку 3.

Для розробки програмного комплексу найбільш доцільно використовувати мову програмування C\# [12].

\section{ВИСНОВКИ}

Проаналізовано наявні методи експертного оцінювання. Вибрано метод ранжування та бальний метод для оцінки результатів технологічного процесу. Виділено фактори, за якими проводитиметься експертне оцінювання результатів технологічного процесу. Сформована математична модель оцінки компетентності експертів, узгодженості експертів та інші статистичні параметри. Розглянуто основні бізнес-процеси предметної галузі на основі SADT-діаграм. Виділені головні сутності під час створення діаграми прецедентів. Також була розроблена діаграма класів. Обгрунтований вибір мови програмування. Розроблений програмний продукт дозволив автоматизувати обчислювальні процеси та дав можливість проводити дослідження 3 великою кількістю експертів та оцінюваних технологічних процесів.

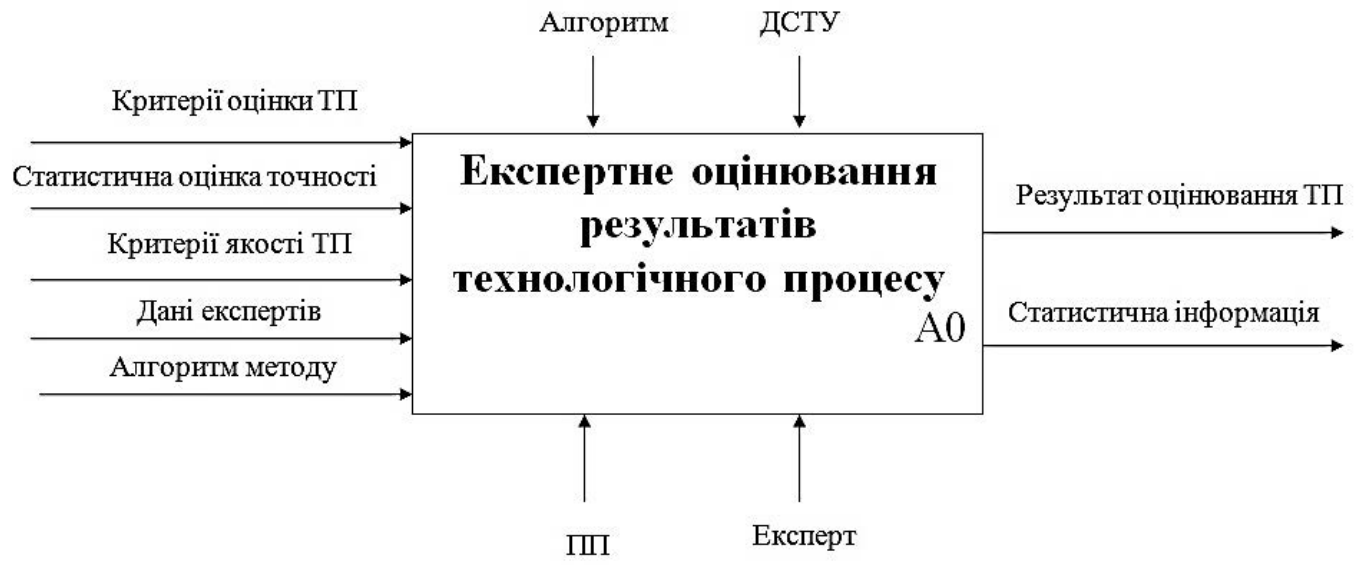

Рис. 1. SADT-діаграма 0-го рівня для бізнес-процесу «Експертне оцінювання результатів технологічного процесу» 


\section{КОМП’ЮТЕРНІ НАУКИ ТА ІНФОРМАЦІЙНІ ТЕХНОЛОГІЇ № З 2020}

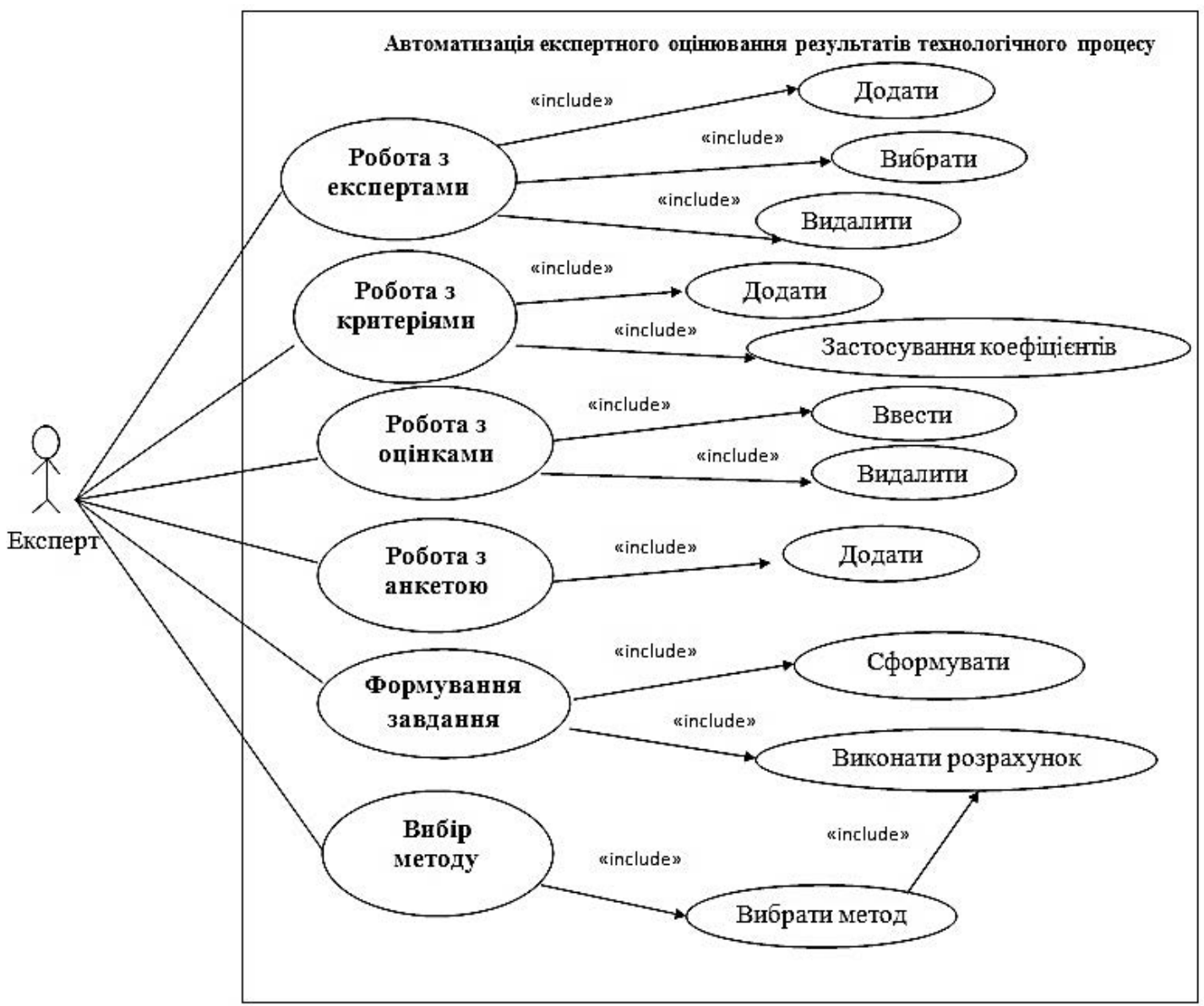

Рис. 2. Діаграма прецедентів «Автоматизація експертного оцінювання результатів технологічного процесу»

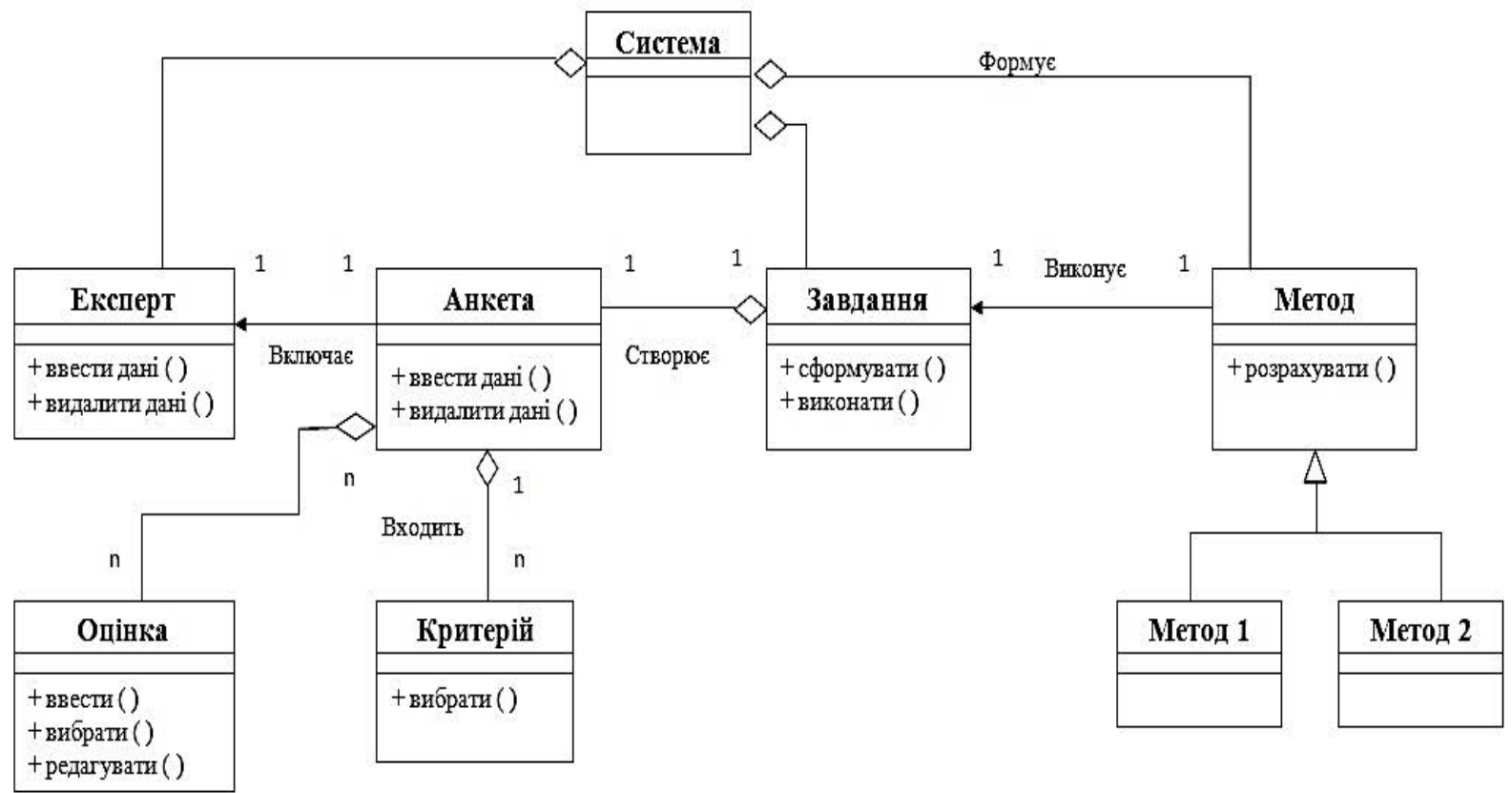

Рис. 3. Діаграма класів для автоматизації експертного оцінювання результатів технологічного процесу 


\section{REFERENCES}

[1] Totsenko, V. G. (2006). Ob unifikatsii algoritmov organizatsii ekspertiz [On the unification of algorithms for the organization of expertise], Problems of legal informatization, No. 2(12), pp. 96-101.

[2] Antonov, A. V. (2004). Sistemnyi analis: uchebnik dlya vuzov [System analysis: a textbook for universities], Vishaya shkola, Moscow, Russia.

[3] Glushkov, V. M. (1970). O prognozirovanii na osnove metoda ekspertnykh otsenok [About forecasting based on the method of expert estimates], Naukovedenie, Prognozirovanie, Informatika, Kiev, Ukraine.

[4] Gordon, T., Helmer, O. (1964). "Long Term Forecast Study Report”, RAND Paper P-2982. RAND Corporation, Santa Monica, California.

[5] Delphi method of expert assessments (2010). Retrieved from: http://finance-and-business.ru/marketing/delphi-method.

[6] Tsyhankov, A. V. (2014), Klasyfikatsyia obyektov s ispolzovaniem metoda ranzhyrovania i genetycheskogo algorytma [Classification of objects using the method of ranking and genetic algorithm], Synergiya, Moscow, Russia.

[7] Socio-economic forecasting (2012). "Methods of expert assessments". Retrieved from: http://uchebnik.online/sotsialnoekonomicheskih-prognozirovanie/metodyi-ekspertnyih-otsenok-32524.

[8] Methods of expert evaluation (2013). Retrieved from: https://habrahabr.ru/post/189626/.

[9] Orlov, A. I. (2002). Ekspertniye otsenki. Uchebnoe posobie [Expert evaluation. Training Allowance], Examen, Moscow, Russia.

[10] Orlov, A. I. (2011). Organizatsionno-ekonomicheskoe modelirovanie. Uchebnik: Chast vtoraya. Ekspertnyie otsenki [Organizational and economic modeling: a textbook: Part Two. Expert ratings], MGTU imeni N. E. Baumana, Moscow, Russia.

[11] Kendal concordation factor (2013). Retrieved from: http://blog.any-p.ru/node/349.

[12] Heilsberg, A., Torgersen, M., Wiltamut, S and Gold, P. (2012). Yazyk programmirovaniya C\# [C\# programming language], Piter, St. Petersburg, Russia.

\section{СПИСОК ВИКОРИСТАНОЇ ЛІТЕРАТУРИ}

[1] Тоценко, В. Г. (2006) Об унификации алгоритмов организации экспертиз. Научно-практический журнал «Проблемы правовой информатизации». Минск. № 2(12). С. 96-101.

[2] Антонов, А. В. (2004) Системный анализ : учебник для вузов. Москва : Высшая школа. 454 с.

[3] Глушков, В. М. (1970) О прогнозировании на основе метода экспертных оценок. Науковедение. Прогнозирование. Информатика. Киев.

[4] Гордон, Т. (1964) Доповідь про дослідження довгострокового прогнозування. / Т. Гордон, О. Хелмер. RAND Paper P-2982. Корпорація RAND, Санта-Моніка, Каліфорнія.

[5] Делфи-метод экспертных оценок. Особенности, сущность, применение. URL: http://finance-and-business.ru/marketing/ delphi-method.html (дата звернення: 23.05.2020).

[6] Циганков, А. В. (2014) Классификация объектов с использованием метода ранжирования и генетического алгоритма. Научно-практический журнал «Прикладная информатика». Москва : Синергия. № 3 (51). С. 60-67.

[7] Методы экспертных оценок. URL: http://uchebnik.online/sotsialno-ekonomicheskih-prognozirovanie/ metodyi-ekspertnyih-otsenok-32524.html (дата звернення: 23.05.2020).

[8] Методы экспертного оценивания. URL: https:/habrahabr.ru/post/189626/ (дата звернення: 23.05.2020).

[9] Орлов, А. И. (2002) Экспертные оценки : учебное пособие. Москва : Экзамен. 31 с.

[10] Орлов, А. И. (2011) Организационно-экономическое моделирование : учебник: Часть вторая. Экспертные оценки. Москва : Издательство МГТУ им. Н. Э. Баумана. 486 с.

[11] Коэффициент конкордации Кендалла. URL: http://blog.any-p.ru/node/349 (дата звернення: 23.05.2020).

[12] Хейлсберг, А. (2012) Язык программирования С\#. Классика Computers Science / А. Хейлсберг, М. Торгерсен, С. Вилтамут та ін. 4-е издание. Санкт-Петербург : «Питер». 784 с.

(C) Т. В. Кухтик, I. А. Гетьман, М. А. Держевецька Дата надходження статті до редакції: 16.10 .2020 Дата затвердження статті до друку: 23.10.2020 